\title{
In vitro cytotoxic activity of anthrapyrazole analogues in human prostate DU-145 and testicular NTERA-2 carcinoma cells
}

\author{
MARIA E. CUEVAS and KURT SEILHEIMER \\ Department of Biology, Southwestern University, Georgetown, TX 78626, USA
}

Received March 6, 2008; Accepted April 22, 2008

\begin{abstract}
Anthrapyrazoles are potent cytotoxic agents that intercalate into DNA, causing DNA strand breaks, inhibition of DNA synthesis and topoisomerase II. In this study, we investigated the in vitro cytotoxic activity of two anthrapyrazole analogues (AP-10 and AP-11) in human prostate (DU-145) and testicular (NTERA-2) carcinoma cells. The cytotoxic activity of these analogues was determined using the MTS cell growth inhibition assay. The $\mathrm{IC}_{50}$ of AP-10 on NTERA-2 and DU-145 cells was found to be 0.2 and $0.4 \mu \mathrm{M}$, respectively. AP-11 inhibited cell growth with an $\mathrm{IC}_{50}$ value of $1.2 \mu \mathrm{M}$ (NTERA-2) and $3.2 \mu \mathrm{M}$ (DU-145). Using trypan blue dye exclusion assay, we were able to confirm the cytotoxic effect of AP-10 and AP-11 on DU-145 cells, thereby distinguishing it from the cytostatic effect. To determine whether cells were able to recover after exposure to the anthrapyrazole analogues, DU-145 and NTERA-2 cells were exposed to the $\mathrm{IC}_{50}$ concentration of AP-10 and AP-11. After a 1-h exposure, fresh media containing either testosterone or dihydrotestosterone were added daily for five days and the cell growth rate was compared to the control. Although cells exposed to AP-10 and AP-11 were able to recover, they never attained the growth rate observed in the control cultures. The DNA fragmentation assay did not provide evidence of apoptosis. In conclusion, our results demonstrated that AP-10 had a higher cytotoxic activity than AP-11, and apoptosis appeared not to be involved in the biological activity of these compounds.
\end{abstract}

\section{Introduction}

Anthrapyrazoles (APs), analogues of anthracyclines, are a specific class of anti-tumor agents that were developed with the intention of lowering the high cardiotoxicity effects caused by their precursors (1). Due to their planar aromatic structure, these compounds are also considered to be exceptional DNA complexing agents $(2,3)$. Furthermore,

Correspondence to: Dr Maria Cuevas, 1001 E University Ave., Department of Biology, Southwestern University, Georgetown, TX 78626, USA

E-mail: cuevasm@southwestern.edu

Key words: anthrapyrazoles, cytotoxic activity, apoptosis studies have shown that the planar anthrapyrazole compounds can cause single and double strand breaks in DNA and are also potent and selective inhibitors of DNA synthesis (4-6). Specifically, studies have shown the clinically tested anthrapyrazoles, losoxantrone and piroxantrone to exert their anticancer effects by inhibiting topoisomerase II activity in advanced breast cancer (7) and a variety of cancer cell lines (8). In addition, losoxantrone, piroxantrone and teloxantrone have proven to be effective antineoplastic drugs in the treatment of breast cancer (9), prostate cancer (10) and acute leukemia (5) but have little or no activity in gastric, colorectal and pancreatic cancers (11). The anthrapyrazole analogues AP-10 and AP-11 were synthesized in the laboratory of Dr F. Guziec (Chemistry/Biochemistry Department, Southwestern University, Georgetown, TX) to determine whether slight structural changes have an effect on compound effectiveness. Compounds AP-10 and AP-11 have two amino substituents that are protonated at a physiological $\mathrm{pH}$ of 7.4 and differ in the presence of a methyl group at $\mathrm{R} 4$ on the $\mathrm{N}-2$ side chain (Fig. 1). The tertiary amino side chain was added in an attempt to increase the electrostatic interaction with DNA (12).

A study by Begleiter et al (12) determined the in vitro cytotoxic activity of newly synthesized anthrapyrazole analogues, including AP-10 and AP-11 on a variety of cell lines. Their study showed these compounds to be less potent than losoxantrone on human breast cancer (MCF-7), human pharynx squamous carcinoma $(\mathrm{FaDu})$ cells, human leukemia (K562) and Chinese hamster ovarian (CHO) cells. Furthermore, the potency of AP-10 and AP-11 varies among the different cell lines. For instance, in the $\mathrm{CHO}$ cell line, AP-11 has a higher cytotoxic effect compared to AP-10, whereas in the K562 cell line there is no difference in their cytotoxic effects. They also demonstrated a lack of correlation between the degree of topoisomerase II inhibition and the degree of cytotoxicity observed.

Studies in our laboratory, using human mammary (MCF-7), endometrial (HEC 1A) and ovarian (SK-OV-3) adenocarcinoma cells have shown AP-10 to have a higher cytotoxic activity than AP-11 (unpublished data). The aims of this project were to investigate the cytotoxic effectiveness of AP-10 and AP-11 on prostate (DU-145) and testicular (NTERA-2pluripotent embryonal) carcinoma cells and to determine the underlying cellular mechanism for their cytotoxicity.

There have been many approaches to the treatment of prostate and testicular cancer. For example, the inhibition of prostate cancer has been accomplished by androgen withdrawal therapy where lutenizing releasing hormone 
(LHRH) inhibitory drugs are used to decrease androgen production (13). Another approach includes the use of doxorubicin, an anthracycline antibiotic, on hormone-refractory prostate cancer producing a response rate ranging from 25 to $84 \%$ in the shrinkage or disappearance of the tumor (14). Furthermore, in a clinical setting, anthrapyrazoles such as losoxantrone have been used to treat prostate cancer with only $22 \%$ of patients responding to the treatment (10). The most common treatments for testicular cancer include surgery, radiation therapy and chemotherapy. However, these treatments result in variable degrees of damage to the germinal epithelium that leads to sub-fertility or infertility (15). Treatments such as cisplatin-based chemotherapy, used to treat testicular germ cell cancer, have shown a recovery of spermatogenesis in $~ 50 \%$ of patients after two years and $80 \%$ recovery after five years. However, a number of patients become infertile and the risk increases with cisplatin dose $(15,16)$. Furthermore, cisplatin forms covalent DNA adducts that are partially mutagenic and cause side effects, with lung toxicity being a major concern $(17,18)$. A study by Ghosh et al (19) looked at vanadocene compounds (metallocenes) and found them to exhibit significant cytotoxicity against testicular (NTERA-2) cells, inducing apoptosis within $24 \mathrm{~h}$.

In the present study we determined the $\mathrm{IC}_{50}$ of the new compounds and the cellular mechanisms involved in the inhibition of cell proliferation. Using the standard MTS cell growth inhibition assay, analogue AP-10 was found to have a higher cytotoxic activity than AP-11. Furthermore, NTERA-2 cells appeared to be more sensitive to these compounds than DU-145 cells. Finally, based on the DNA-fragmentation assay, apoptosis appeared not to be the underlying cellular mechanism of the cytotoxic effect of AP-10 and AP-11.

\section{Materials and methods}

Chemicals. Eagle's Minimal Essential Media (EMEM) with Earle's Basal Saline Solution (EBSS) and Dulbecco's modified Eagle's medium (DMEM) were purchased from American Type Culture Collection (ATCC, Manasas, VA). Fetal bovine serum (FBS) and charcoal stripped fetal bovine serum (CSFBS) were obtained from Invitrogen (Chicago, IL). Lglutamine, penicillin/streptomycin/glutamine (PSG), trypsin, sodium bicarbonate, sodium pyruvate, glucose and nonessential amino acids were from Gibco (Grand Island, NY). Testosterone and dihydrotestosterone (DHT) were purchased from Sigma (St. Louis, MO).

Cell lines and tissue culture conditions. Human prostate (DU-145) and testicular carcinoma cells (NTERA-2) were purchased from ATCC. DU-145 cells were maintained in EMEM with EBSS, supplemented with $2 \mathrm{mM}$ L-glutamine, $1 \mathrm{mM}$ sodium pyruvate, $0.1 \mathrm{mM}$ non-essential amino acids, $1.5 \mathrm{mg} / \mathrm{ml}$ sodium bicarbonate, $1 \% \mathrm{PSG}$ and $10 \% \mathrm{FBS}$. NTERA-2 cells were maintained in DMEM with $4 \mathrm{mM} \mathrm{L-}$ glutamine, $1.5 \mathrm{mg} / \mathrm{ml}$ sodium bicarbonate and $4.5 \mathrm{mg} / \mathrm{ml}$ glucose, $1 \%$ PSG and $10 \%$ FBS. Cells were grown in 25 or $75 \mathrm{~cm}^{2}$ culture flasks at $37^{\circ} \mathrm{C}$ in a $5 \% \mathrm{CO}_{2}$ atmosphere.

Compounds. Anthrapyrazole analogues (AP-10 and AP-11) were a generous gift from Dr Frank Guziec of the Chemistry/

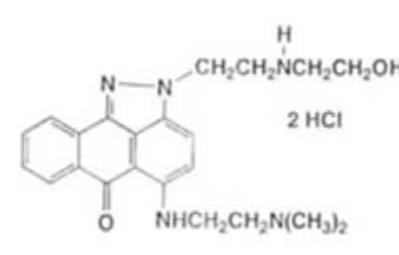

AP-10

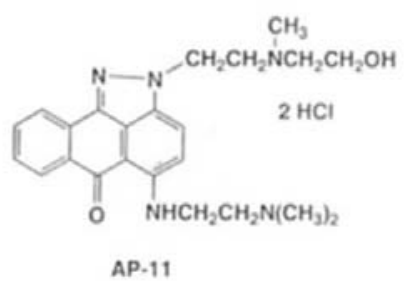

AP.11
Figure 1. Chemical structure of anthrapyrazole analogues AP-10 and AP-11.

Biochemistry Department at Southwestern University. AP-10 and AP-11 were dissolved in phosphate-buffered saline (PBS), stored and protected from light in stock solutions of 89.0 and $249.7 \mu \mathrm{M}$ at $4^{\circ} \mathrm{C}$, respectively.

Cytotoxicity assay. DU-145 and NTERA-2 cell lines were seeded in quadruplicates $(50,000$ cells/well) into 96-well plates and allowed to recover for $24 \mathrm{~h}$. Cultures (70-80\% confluent) were incubated in $200 \mu \mathrm{l}$ of media containing different drug concentrations (final concentrations ranged from 0.1 to $20.0 \mu \mathrm{M}$ ) for $1 \mathrm{~h}$. Cells were then washed with PBS and allowed to recover in serum containing media for $48 \mathrm{~h}$. Cell viability was determined using MTS CellTiter $96{ }^{\circledR}$ AQueous One Solution Cell Proliferation Assay (Promega). Briefly, $20 \mu 1$ of [3-(4,5-dimethylthiazol-2-yl)-5-(3-carboxymethoxphenyl)-2-(4-sulfophenyl)-2H-tetrazolium, inner salt; MTS] and an electron-coupling reagent (phenazine ethosulfate; PES) were added to each well. Plates were incubated for $1-3 \mathrm{~h}$ at $37^{\circ} \mathrm{C}$ in a humidified $5 \% \mathrm{CO}_{2}$ atmosphere. Absorbance was recorded at $490 \mathrm{~nm}$ using an ELISA plate reader (Bio-Rad). The $\mathrm{IC}_{50}$ was determined from the doseresponse curves of three different experiments.

DNA fragmentation assay. DNA extracts were prepared from adherent and floating DU-145 and NTERA-2 cells treated with the $\mathrm{IC}_{50}$ concentrations of AP-10 and AP-11, using a DNA laddering kit provided by Cayman Chemicals (Ann Arbor, MI). Samples were analyzed on $2 \%$ agarose minigel and visualized with ethidium bromide under ultraviolet light.

Cell death vs. cell growth inhibition. Under the assumption that AP-10 and AP-11 act similarly on the two cell lines, DU-145 cells $\left(5 \times 10^{4}\right.$ cells/well) were seeded in duplicate in 6 -well plates and incubated for $48 \mathrm{~h}$ under the conditions previously described. Cells were exposed for $1 \mathrm{~h}$ to AP-10 or AP-11 using the $\mathrm{IC}_{50}$ concentrations determined by MTS assay and allowed to recover for $48 \mathrm{~h}$ in serum-containing media. Cell viability was determined by a trypan blue dye exclusion assay. Cell counts of two random wells were performed during plating to confirm the uniformity of cell distribution and to establish the actual initial number of cells plated, and $48 \mathrm{~h}$ later before drug exposure to confirm the population doubling time (PDT).

Cell recovery. In order to determine whether treatment with AP-10 was reversible and if so how rapidly cells would recover from the cytotoxic effect, logarithmically growing DU-145 and NTERA-2 cells $\left(5 \times 10^{4}\right.$ cells/well) were seeded 
Table I. Cytotoxic activity of AP-10 and AP-11.

\begin{tabular}{lcc}
\hline & AP-10 & AP-11 \\
\hline DU-145 cells & $0.4 \mu \mathrm{M}$ & $3.2 \mu \mathrm{M}$ \\
NTERA-2 cells & $0.2 \mu \mathrm{M}$ & $1.2 \mu \mathrm{M}$ \\
\hline
\end{tabular}

Cells were seeded in quadruplicate in 96-well plates. Cultures (70$80 \%$ confluent) were incubated in $200 \mu 1$ of media containing different drug concentrations $(0.1-20 \mu \mathrm{M})$ for $1 \mathrm{~h}$.

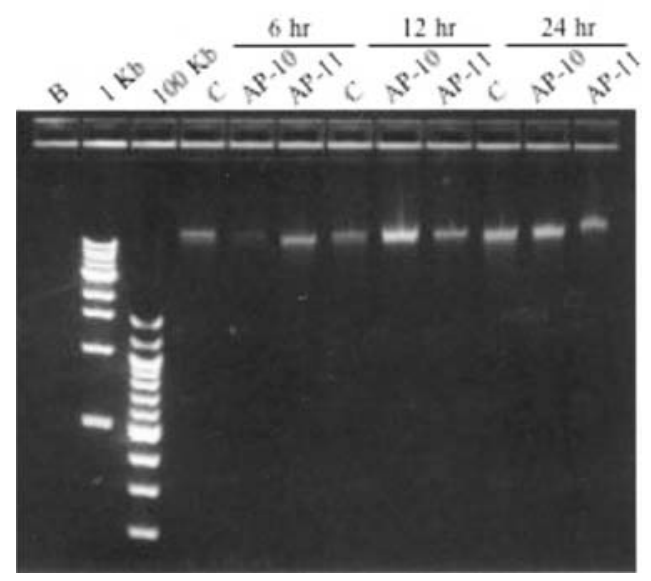

Figure 2. DNA fragmentation analysis after 6, 12 and $24 \mathrm{~h}$. DNA extracts were prepared from cells treated and incubated as described in Materials and methods. The DNA was visualized on a $2 \%$ agarose gel with ethidium bromide under ultraviolet light. The typical apoptotic DNA laddering pattern (180-200 bp) was not observed after exposure to AP-10 or AP-11.

in duplicate in 6-well plates and incubated for $48 \mathrm{~h}$. Cells were then exposed for $1 \mathrm{~h}$ to their respective $\mathrm{IC}_{50}$ concentration of AP-10. After exposure, the cells were washed with PBS and incubated with media containing $10 \%$ CSFBS in the absence or presence of $1.0 \mu \mathrm{M}$ dihydrotestosterone (DHT) or testosterone $(\mathrm{T})$ for 5 days. To ensure a proper nutrient content and effective drug concentration the medium was replaced daily. Steroids were used in an ethanol vehicle, did not exceed $0.1 \%$ $(\mathrm{v} / \mathrm{v})$ in the final culture media. Cell viability was determined every $24 \mathrm{~h}$ for 5 days by trypan blue dye exclusion assay.

\section{Results}

Determination of the cytotoxic activity of AP-10 and AP-11 on NTERA-2 (testicular) and DU-145 (prostate) cancer cells in vitro. NTERA-2 human testicular and DU-145 human prostate cancer cells were treated with a range of concentrations of AP-10 or AP-11 for $1 \mathrm{~h}$. The cytotoxic activity was then determined using the standard MTS assay. The two analogues inhibited cell growth with $\mathrm{IC}_{50}$ values that ranged between 0.2 and $3.2 \mu \mathrm{M}$ (Table I). In general, AP-10 showed a higher cytotoxicity than AP-11 and lower $\mathrm{IC}_{50}$ values were observed in the NTERA-2 cell line.

DNA fragmentation assay. To determine whether apoptosis was the underlying cellular mechanism by which AP-10 and

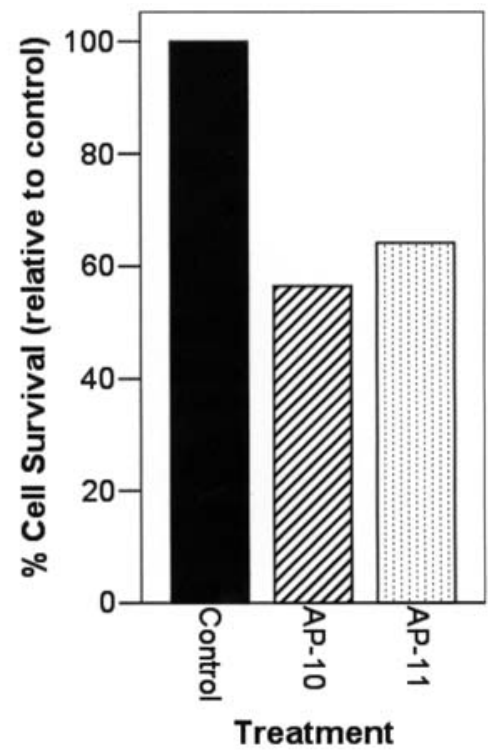

Figure 3. Differentiation between the cytostatic and cytotoxic effects of AP-10 and AP-11. In order to distinguish between the cytotoxic and cytostatic effects of the drugs, DU-145 cells were incubated as described in Materials and methods. An actual cell count confirmed the cytotoxic effect of the analogues as observed by the decrease in the cell number. Furthermore, the $\sim 50 \%$ inhibition expected was observed.

AP-11 exerted their cytotoxicity, prostate and testicular cells were exposed to AP-10 or AP-11 for $1 \mathrm{~h}$. DNA was extracted from adherent and floating cells $48 \mathrm{~h}$ after exposure and subjected to electrophoresis on a $2 \%$ agarose gel. No DNA laddering was observed in either cell line exposed to either compound (data not shown). Concerned with the possibility of having extracted the DNA past a time point where DNA fragmentation could be observed, we decided under the assumption that AP-10 and AP-11 act similarly on the two cell lines, to extract DNA only from DU-145 at 6,12 and $24 \mathrm{~h}$ after exposure to AP-10 or AP-11. Fig. 2 shows the results of the DNA fragmentation assay using only DU-145 samples, where we again observed an intact DNA with no indication of degradation or fragmentation. These results suggest that apoptosis was not the underlying cellular mechanism by which these compounds inhibited cell growth.

Cell death vs. cell inhibition. Since no evidence of apoptosis was observed, we wanted to differentiate between the cytotoxic and cytostatic effects of AP-10 and AP-11. In order to do this, DU-145 cells were incubated in the presence of the $\mathrm{AP}-10$ and $\mathrm{AP}-11 \mathrm{IC}_{50}(0.4$ and $3.2 \mu \mathrm{M}$, respectively $)$ value as described in Materials and methods. Using trypan blue dye exclusion assay, the percentage of survival of the cells exposed to AP-10 and AP-11 was determined to be 56.46 and $64.21 \%$, respectively, when compared to the number of cells plated at the beginning of the experiment (Fig. 3). Therefore, we observed the $\sim 50 \%$ inhibition expected, confirming the cytotoxic effects of AP-10 and AP-11.

Effect of testosterone and dihydrotestosterone on DU-145 and NTERA-2 cells. In order to determine whether the anthrapyrazole analogue treatment was reversible and if so how rapidly cells would recover from the cytotoxic effect, 

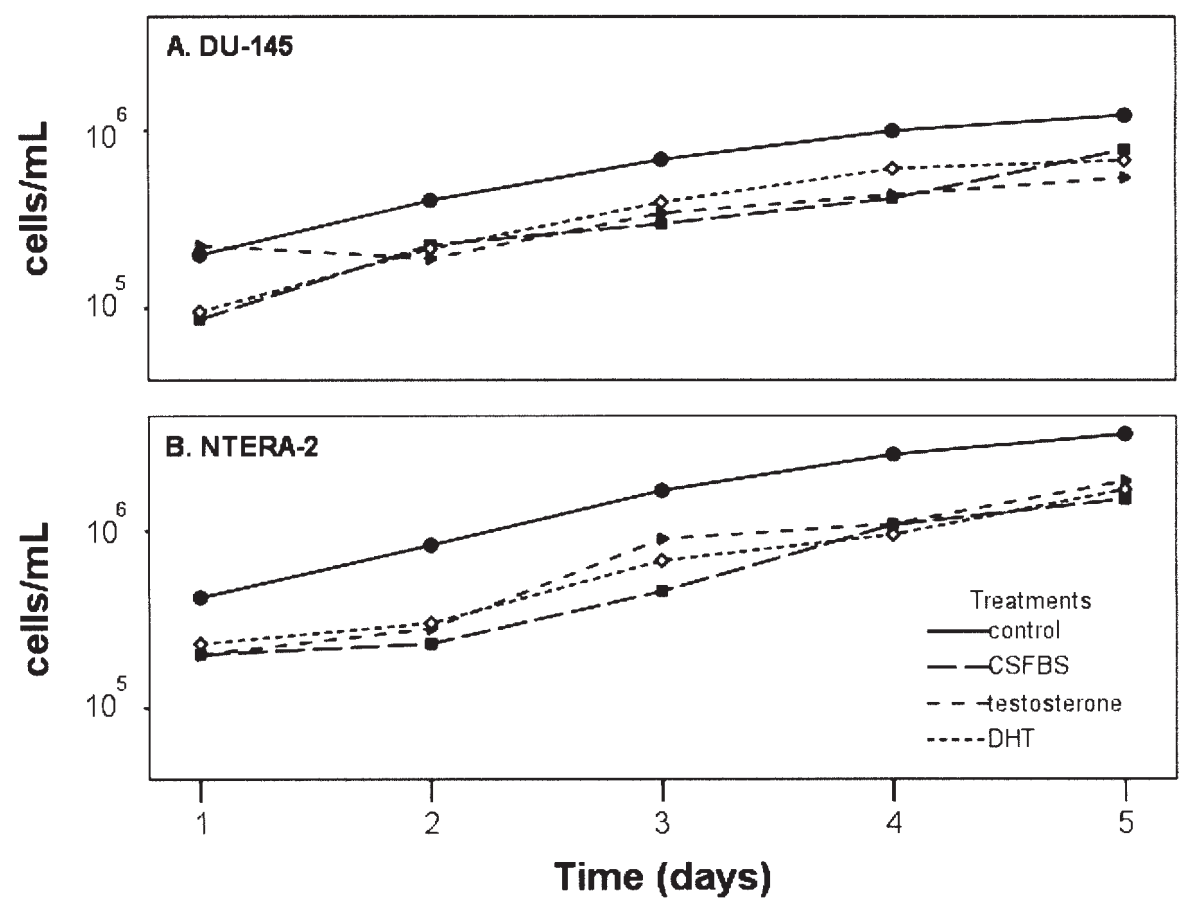

Figure 4. Prostate DU-145 (4A) and testicular NTERA-2 (4B) recovery rate after exposure to AP-10 in the presence or absence of testosterone or DHT. Media containing no hormones or either testosterone or DHT were replaced daily for 5 days and cell viability was determined each day by the trypan blue dye exclusion assay. Although the cells exposed to AP-10 were able to recover, neither testosterone nor DHT were able to increase the cell proliferation rate when compared to the control.

DU-145 and NTERA-2 cells were exposed to the $\mathrm{IC}_{50}$ of AP-10 ( 0.4 and $0.2 \mu \mathrm{M}$, respectively) and incubated as described in Materials and methods. As expected, the cells exposed to AP-10 were unable to recover compared to the untreated cells. As seen in Fig. 4A, cells incubated in media containing testosterone, DHT or $10 \%$ CSFBS showed a growth rate of $1.03 \times 10^{5}, 7.6 \times 10^{4}$ and $7.4 \times 10^{4}$ cells/day, respectively. In contrast, the growth rate of untreated cells was determined to be $2.86 \times 10^{5}$ cells/day (3-4 fold increase).

When comparing the growth rate of NTERA-2, we observed that testosterone increased the growth rate by almost 3-fold when compared to the cells incubated in media containing $10 \%$ CSFBS $\left(6.2 \times 10^{5}\right.$ vs $2.25 \times 10^{5}$ cells/day). Notably, DHT, a more potent androgen, increased the growth rate only marginally $\left(3.8 \times 10^{5}, 1.7\right.$-fold $)$ when compared to $10 \%$ CSFBS. As expected, cells that were not exposed to AP-10 and kept in DMEM/10\% FBS throughout the entire experiment, showed the fastest growth rate $\left(8.5 \times 10^{5}\right.$ cells/day $)$.

\section{Discussion}

The present study attempted to look at the in vitro cytotoxic effect of the anthrapyrazole analogues AP-10 and AP-11 on human prostate cancer (DU-145) and testicular carcinoma (NTERA-2) cells. Using an MTS assay, the $\mathrm{IC}_{50}$ value of AP-10 on the NTERA-2 and DU-145 cells was determined to be 0.2 and $0.4 \mu \mathrm{M}$, respectively. In contrast, AP-11 inhibited cell growth with an $\mathrm{IC}_{50}$ value of $1.2 \mu \mathrm{M}$ (NTERA-2) and $3.2 \mu \mathrm{M}$ (DU-145). Previous studies in our laboratory had determined that there is approximately a 2 -fold difference in the cytotoxic activity of AP-10 compared to AP-11 among breast (MCF-7), endometrial (HEC 1A) and ovarian SK-OV-3 cancer cell lines (unpublished data). In contrast, in the present study we observed a 6- to 8-fold difference between the $\mathrm{IC}_{50}$ values of AP-10 and AP-11 indicating that AP-10 has a higher cytotoxic activity than AP-11. Furthermore, NTERA-2 cancer cells appeared to be slightly more susceptible to the cytotoxic effect of these compounds. A study by Begleiter et al (12) showed AP-10 to have a greater cytotoxicity than AP-11 (5- to 23-fold difference) in breast (MCF 7) and pharynx squamous $(\mathrm{FaDu})$ carcinoma cells, but a lower cytotoxicity in Chinese hamster ovarian $(\mathrm{CHO})$ cells, while in the same study, AP-10 and AP-11 had similar cytotoxic effects in the human leukemia cell line (K565). Although a 2 -fold difference may not be biologically relevant, a difference of 8 -fold is noteworthy. One possible reason for the difference in the cytotoxicity of the compounds among the different cell lines may be due to the presence of metabolic enzymes that would render the particular anthrapyrazole analogue inactive. Thus increased concentrations may be needed to promote cell death at levels of $50 \%$. In this study it appears that the addition of a methyl group at $\mathrm{R} 4$ on the $\mathrm{N}-2$ side chain on AP-11 decreases its ability to interact with DNA or increases its vulnerability for metabolism, resulting in the lower cytotoxic effect observed in the two cell lines.

In order to determine whether apoptosis was the underlying cellular mechanism behind the observed cytotoxic effect of AP-10 and AP-11, DNA was extracted from DU-145 and NTERA-2 cells $48 \mathrm{~h}$ after exposure to the $\mathrm{IC}_{50}$ concentration of the analogues. We did not observe the typical 180-200 bp units expected should apoptosis have occurred. The absence of DNA laddering observed in this study may have resulted from extracting DNA from surviving cells that had enough time to recover and re-establish growth. Therefore, to 
circumvent this possibility, we extracted DNA from DU-145 cells at 6,12 and $24 \mathrm{~h}$ after exposure to the anthrapyrazole analogues. Again, no DNA laddering was observed. Together, these results suggest that apoptosis is unlikely to be the biological underlying mechanism of the anthrapyrazole's cytotoxic effect in the cell lines used in this study. It is possible, however, that cells treated with AP-10 or AP11 may begin programmed cell death, but undergo secondary necrosis, in which case no DNA fragmentation would be observed (20). Another possibility is that AP-10 and AP-11 may arrest cell growth, that is, have a cytostatic rather than a cytotoxic effect.

To test this possibility DU-145 cells were exposed to the $\mathrm{IC}_{50}$ values of AP-10 and AP-11 and cell viability was assessed using trypan blue dye exclusion assay. Our results revealed the expected $50 \%$ cell inhibition confirming the cytotoxic effect of the anthrapyrazole analogues. A study by Supino et al (6) demonstrated the ability of the anthrapyrazole BBR 3438 to promote significant cell death only after $144 \mathrm{~h}$ of exposure, and suggest delayed apoptosis as the primary mode of cell death. In the present study, cells were exposed for only $1 \mathrm{~h}$ followed by DNA extraction $48 \mathrm{~h}$ later. Thus, it is possible that in order to observe apoptosis, a longer exposure time to the analogues is needed.

Future studies to determine the biological mechanism by which AP-10 and AP-11 exert their cytotoxicity may include determining whether AP-10 and AP-11 inhibit topoisomerase II and whether its inhibition is correlated with the degree of cytotoxicty observed. However, a study by Begleiter et al (12), failed to demonstrate a correlation between the degree of topoisomerase II inhibition and the cytotoxic effect of all the anthrapyrazoles tested, suggesting that another cellular mechanism may be involved. Several studies have also demonstrated the down-regulation of $\mathrm{Bcl}-2$ that likely reflects an early cellular response to the cytotoxic effect of the drugs, which occurs at a time before substantial cell death can be detected $(6,21)$. Therefore, an analysis of Bcl-2 expression in cells exposed to AP-10 and AP-11 may be valuable.

We were also interested in investigating the effect of hormones via steroid-receptor independent pathways. In vivo effects of anthrapyrazole analogues must take into account the physiological hormonal milleu and their effect on cellular recovery. DU-145 and NTERA-2 cells were exposed to the $\mathrm{IC}_{50}$ value of AP-10 and allowed to recover in the presence or absence of androgens. When comparing the rate of proliferation (cells/day) of DU-145 cells in the presence of testosterone versus the rate seen with DHT or CSFBS, we observed a 1.4 -fold increase in the cell growth rate. However, cells exposed to the different treatments did not attain the growth rate seen in the control cells. The lack of hormonal response in the DU-145 is consistent with the absence of androgen receptors in this cell line (9). Therefore, we can conclude that DU-145 cells do not have an alternate receptor-independent pathway. When comparing the growth rate in the NTERA-2 cells, we observed that DHT, a more potent androgen, marginally increased the growth rate when compared to CSFBS. In contrast, testosterone increased the growth rate by almost 3-fold when compared to cells in CSFBS, but the growth rate of testosterone-treated cells did not reach the growth rate observed in the untreated cells. It appears that
AP-10 is capable of promoting cell death. However, upon removal, the surviving cells have the capacity to proliferate in the absence of androgens. Under physiological conditions the testis are constantly exposed to concentrations of androgens that may promote growth after treatment with anthrapyrazole analogues but at a slower rate.

In conclusion, our results demonstrate that AP-10 has a higher cytotoxic activity than does AP-11 on DU-145 and NTERA-2 cells, and their cytotoxicity results in cell death. However, apoptosis appears not to be involved in mediating the biological activity of these compounds.

\section{Acknowledgements}

This work was partially supported by the Fleming Fund, Southwestern University. The authors are indebted to Dr Frank Guziec for providing the anthrapyrazole analogues, to Dr Romi Burks and Dr Martin Gonzalez for their graphic technical help and Dr Maria Todd for her technical expertise.

\section{References}

1. Leopold WR: Anthrapyrazoles, a new class of intercalating agents with high-levels, broad spectrum activity against murine tumors. Cancer Res 45: 5532-5539, 1985.

2. Hartley JA, Reszka K, Zuo ET, Wilson WD, Morgan AR and Lown JW: Characteristics of the interacton of anthrapyrazole anticancer agents with deoxyribonucleic acids: structural requirements for DNA binding intercalation and photosensitization. Mol Pharmacol 33: 265-271, 1988.

3. Showalter HD, Johnson JL, Hoftiezer JM, Turner WR, Werbel LM, Leopold WR, Shilllis JL, Jackson RC and Elslager EF: Anthrapyrazole anticancer agents. Synthesis and structure-activity relationships against murine leukemias. J Med Chem 30: 121-131, 1987.

4. Fry DW, Boritzki TJ, Besserer JA and Jackson RC: In vitro DNA strand scission and inhibition of nucleic acid synthesis in L 1210 leukemia cells by a new class of DNA complexes the anthra [1,9-cd]pyrazol-6(2H)-ones (anthrapyrazoles). Biochem Pharmacol 34: 3499-3508, 1985.

5. Showalter HDH, Fry DW, Leopold WR, Lown JW, Plambeck JA and Rezka K: Design, biochemical pharmacology, electrochemistry and tumor biology of anti-tumor anthrapyrazoles. Anticancer Drug Des 1: 73-85, 1986.

6. Supino R, Polizzi D, Pavesi R, Pratesi G, Guano F, Capranico G, Palumbo M, Sissi C, Richter S, Beggiolin G, Menta E, Pezzoni G, Spinellli S, Torriani D, Carenini N, Dal Bo L, Facchinetti F, Tortoreto M and Zunino F: A novel 9-aza-anthrapyrazole effective against human prostate carcinoma xenografts. Oncology 61: 234-242, 2001.

7. Talbot DC, Smith IE and Mansi JL: Anthrapyrazole CI941: a highly active new agent in the treatment of advance breast cancer. J Clin Oncol 9: 2141-2147, 1991.

8. Lectertre F, Kohlhagen G, Paull KD and Pommier Y: Topoisomerase II inhibition and cytotoxicity of the anthrapyrazoles DuP 937 and DuP 941 (Losoxantrone) in the National Cancer Institute preclinical antitumor drug discovery screen. J Nat Can Inst 86: 1239-1244, 1994.

9. Ingle JN, Kuross SA, Maillard JA, Loprinizi CL, Jung S, Nelimark RA, Krook JE and Long HJ: Evaluation of piroxantrone in women with metastatic breast cancer and failure on non-anthracycline chemotherapy. Cancer 74: 1733-1738, 1994.

10. Huan SD, Natale RB, Stewart DJ, Sartiano GP, Stella PJ, Roberts JD, Symes Al and Finizio M: A multicenter phase II trial of losoxantrone (DuP-941) in hormone-refractory metastatic prostate cancer. Clin Cancer Res 6: 1333-1336, 2000.

11. Gogas H and Mansi JL: New drugs. The anthrapyrazoles. Cancer Treat Rev 21: 541-552, 1996.

12. Begleiter A, Lin D, Larson KK, Lang J, Wu X, Cabral T, Taylor H, Guziec LJ, Kerr PD, Hasinof BB and Guziec FS: Structure-activity studies with cytotoxic anthrapyrazoles. Oncol Rep 15: 1575-1580, 2006. 
13. Gleave ME, Brkuchovsky N, Moore MJ and Venner P: Prostate cancer: 9 treatments of advance disease. CMAJ 160: 225-232, 1999.

14. Torti FM, Aston D, Lum BL, Kohler M, Williams R, Spaulding JT, Shortliffe L and Freiha FS: Weekly doxorubicin in endocrine-refractory carcinoma of the prostate. J Clin Oncol 1: 477-482, 1983.

15. Dearnly DP, Huddart RA and Horwich A: Regular review: Managing testicular cancer. BMJ 322: 1583-1588, 2001.

16. Howell SJ and Shalet SM: Testicular function following chemotherapy. Hum Reprod Update 7: 363-369, 2001.

17. Kuo YL, Liu AH and Marks TJ: Metallocine interactions with DNA and DNA-processing enzymes. In: Metal Ions in Biological Systems. Sigel H and Sigel A (eds). Vol. 31, Marcel Dekker, NY, pp53-85, 1995.

18. Dewit R, Roberts JT, Wilkinson PM, deMudder PH, Mead GM, Fossa SD, Cook P, de Prijck L, Stenning S and Collette L: Equivalence of three or four cycles of bleomycin, etoposide, and cisplatin chemotherapy and of a 3- or 5-day schedule in goodprognosis germ cell cancer: a randomized study of the European Organization for Research and Treatment of Cancer Genitourinary Tract Cancer Cooperative Group and the Medical Research Council. J Clin Urol 19: 1629-1640, 2001.
19. Ghosh P, D'Cruz OJ, Narla RK and Uckun FM: Apoptosisinducing vanadocene compounds against human testicular cancer. Clin Cancer Res 6: 1536-1545, 2000.

20. Kanduc D, Mittelman A, Serpico R, Sinigaglia E, Sinha AA, Natale C, Santacroce R, Grazia Di Corcia M, Lucchese A, Dini L, Pani P, Santacroce S, Simone S, Bucci R and Farber E: Cell death: apoptosis versus necrosis. Int J Oncol 21: 164-170, 2002.

21. Halder S, Chintapalli J and Croce CM: Taxol induces Bcl-2 phosphorylation and death of prostate cancer cells. Cancer Res 56: 1253-1255, 1996. 